\title{
Frequency control reserve with multiple micro grid participation for power system frequency stability
}

\author{
Mohamad Syamin Bin Zainal Abidin ${ }^{1}$, Norhafiz Bin Salim² ${ }^{2}$ Aimie Nazmin Bin Azmi ${ }^{3}$, \\ Nor Aira Binti Zambri ${ }^{4}$, Takao TSUJI ${ }^{5}$ \\ ${ }^{1,2,3}$ Faculty of Electrical and Engineering, Universiti Teknikal Malaysia Melaka, Malaysia \\ ${ }^{4}$ Faculty of Engineering Technology, Universiti Tun Hussein Onn, Malaysia \\ ${ }^{5}$ Yokohama National University, Japan
}

\begin{tabular}{l}
\hline \hline Article Info \\
\hline Article history: \\
Received Jan 21, 2019 \\
Revised Apr 24, 2019 \\
Accepted May 15, 2019 \\
\hline
\end{tabular}

\section{Keywords:}

Frequency control reserve

Frequency stability

Micro-grids

\begin{abstract}
The introduction of this micro grids into the conventional distribution network system forces a new challenge to the system operation. The failure factor of the power system performance essentially due to the limitation of electrical power generation in which could not meet the load demand. In order to maintain the frequency stability of the system, the power sources must be matched instantaneously among all generators and constantly supply to the load demand. A deviation of system frequency from the set-point value will affect the entire stability of power system network. This paper investigates the impact of utilizing multiple micro grids in supporting and facilitating on grid's frequency. A method called Frequency Control Reserve (FCR) is introduced, with intention to share the excessive power from all available micro grids. These power will be controlled effectively before being injected into the main grid to stabilize the power frequency. Simulation using MATLAB Simulink have been used to simulate the result and shows great potential to be integrated with distributed generation i.e. solar photovoltaic (PV) for Malaysia power system vicinity.
\end{abstract}

Copyright $\odot 2019$ Institute of Advanced Engineering and Science. All rights reserved.

\section{Corresponding Author:}

Norhafiz Bin Salim,

Faculty of Electrical Engineering,

Universiti Teknikal Malaysia,

Jalan Hang Tuah Jaya, Durian Tunggal, 76100 Melaka, Malaysia.

Email: norhafiz@utem.edu.my

\section{INTRODUCTION}

In recent years, rapid growth from worldwide to exploit alternative energy resources emerged due to the shortage of fossil fuels and atomic energy crisis issue which allow the development generation technologies into a small scale [1]. A typical model of micro grids typically discrete energy system comprising distributed energy resources (including demand management, storage, and generation) and loads capable of operating in parallel with, or independently from the main power grid. The increasing of new energy industry make the micro grids play an important role in power system network [2, 3]. A micro grid can works in two modes, which is grid-connected mode and islanded mode [4]. The micro grid works in gridconnected mode under normal conditions which is connected to the grid, being either partly supplied from it or injecting power into it. Meanwhile, the micro grid can shift to islanded mode when a fault happened in the grid under emergency circumstances which disconnects from the grid and operates independently. In short, the possibility of having a network contingency is being reduced as this micro grid contains many small units so the chances of power loss generation at a time decreases.

Incident of blackout worldwide since 1965 have attracted many researchers to investigate power system stability problems [5-7]. Frequency stability for instance play a big role in power system that relies on an active power balance and should be maintained within certain operating limits. Any interruptions or 
contingencies will affect the frequency of the system and contribute to power deficiency [8, 9]. Restoration capability between generation and load must be achieved with minimum loss of load and this bring a great challenge for power system operator while exposing to various contingencies and disturbances during real time operation [10]. The restoration process for under or over frequency must have fast dynamic assessment avoiding large scale blackout by incorporating demand response [11-13]. The performance of generator in conventional power stations are depending on the performance of all ancillary electric motor drives. If low speed occurs due to low frequency, it will affect the output for the power generator and will lead to shutdowns of the power plant [14-16]. Load Shedding will be the last resort to encounter instability of frequency and voltage and a lot of strategy has been developed to comprehend the stability issues especially on cascading effect [17-20]. Battery energy storage system offer great helps for under frequency scenario especially when associated with high renewable energy participations [21-26].

Although it exists so many methods from most of previous researcher on frequency regulation but they have not discussed the capability of micro grid with the participation of renewable energy to some extends. So, in this investigation, the micro grid development i.e. single and multiple are determined via frequency control reserve (FCR) strategy alongside with battery energy storage system (BESS) which incorporated the dead band control. This control mechanism was analyzed for its dynamic performance during peak load demand situation. In this simulation, all the related results have been discussed and compared deliberately.

\section{FREQUENCY CONTROL RESERVE (FCR)}

Recent power systems are divided into many areas. Any regional areas are generally interconnected to its neighbouring area. Tie lines act to connect all the area involved for power sharing or power import and export. The power flow between different areas regulates at times and it is vital keeping the frequency constant [9]. The system frequency increases when the load decreases if $\Delta$ Pref is stored at zero. Likely, the frequency may decrease if the load increases too. Hence, it is necessary to maintain the frequency so that $\Delta f=0$. Area 1 may export the pre-determined amount of power to Area 2 while importing the pre-determined amount of power from Area 3. However, it is expected to meet the above duties, each area will change its own load change, i.e. increase the generation to supplying additional loads in the area or lower the generation when demand for load in the area decreases. Despite doing this Area 1 must maintain its obligations to Areas 2 and 3 as far as import and export power by mean of available resources, including the mechanical inertia from interconnected generator. It is targeted to suppress the frequency within $0.5 \mathrm{~Hz}$ and below for using the support from the frequency control reserve strategy (FCR) from both single micro grid and multiple micro grids. It is supposed that with a greater number of micro grid integration would benefit more to realize for zero frequency deviation, but they must particularly design to ensure local operation is under controlled and by then being adjusted to fit for power exported so called reserve power to facilitate under above mentioned proposed strategy.

\subsection{Automatic Generation Control}

Automatic generation control (AGC) is a system to adjust the power output of various generators in different power plants, in response to load change. Basically, in automatic generation control (AGC), all generating sets could contribute in regulating frequency deviations evolved due to power imbalance scenario Frequent adjustments for the generator output are necessary in every second during the operation as to maintain equibilirium level in entire process. The frequency deviation can be measured by measuring the frequency of the system; if it is increasing, more power is generated than the one used, which causes all machines in the system to accelerate and vice versa.

The AGC test model system is designed in MATLAB Simulink. It has 4 different types of conventional generation combined together and the power from the load is minus to get the power mismatch, $\triangle P o u t$. The inertia model will analyze $\triangle P$ Pout before converting it to $\Delta f$. The LFC model will send back the signal to complete one cycle. This model [27] is then being duplicates but with another two different set of model with different capacity of generation and demand as to illustrate for small area, medium area and large area respectively. 


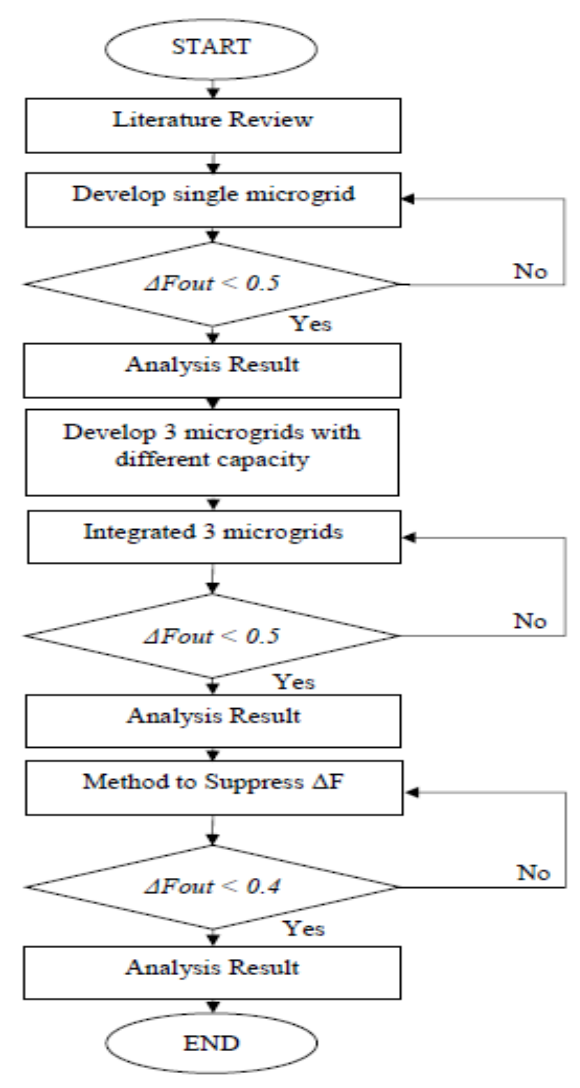

Figure 1. Project implementation flowchart

\section{RESULTS AND ANALYSIS}

In this section, few model, event and cases have been carried out in detail on frequency regulation to emphasize and relate on real opeartion conditon. These approaches have been designed deliberate for an interconnected power system with deployment of multiple micro grids.

\subsection{Single Micro Grid}

The test model that has been developed is Automatic Generation Control (AGC) System during off-peak. The reason for selecting just the off-peak load is mainly because the rate of change of frequency definitely increases and becomes severe to the reduction of the final load demand. For single micro grid namely MG1, 3 cases already develop as to investigate how the power can affect the frequency system. The specification for all cases are shown in Table 1.

Table 1. The Conditon for All Cases

\begin{tabular}{cc}
\hline Case & Condition \\
\hline 1 & $\mathrm{P}_{\mathrm{S}}=\mathrm{P}_{\mathrm{L}}$ \\
2 & $\mathrm{P}_{\mathrm{S}}>\mathrm{P}_{\mathrm{L}}$ \\
3 & $\mathrm{P}_{\mathrm{S}}<\mathrm{P}_{\mathrm{L}}$ \\
\hline
\end{tabular}

In Figure 2, it shows the tie-line power flow whereby it can be predicted for higher the power, the higher the frequency would be generated. Meanwhile in Figure 3, it shows the frequency deviation of the power system with total load demand. This model is stable because the frequency deviation fluctuates between the maximum tolerances for stability of power system which is $\pm 0.5 \mathrm{~Hz}$. 


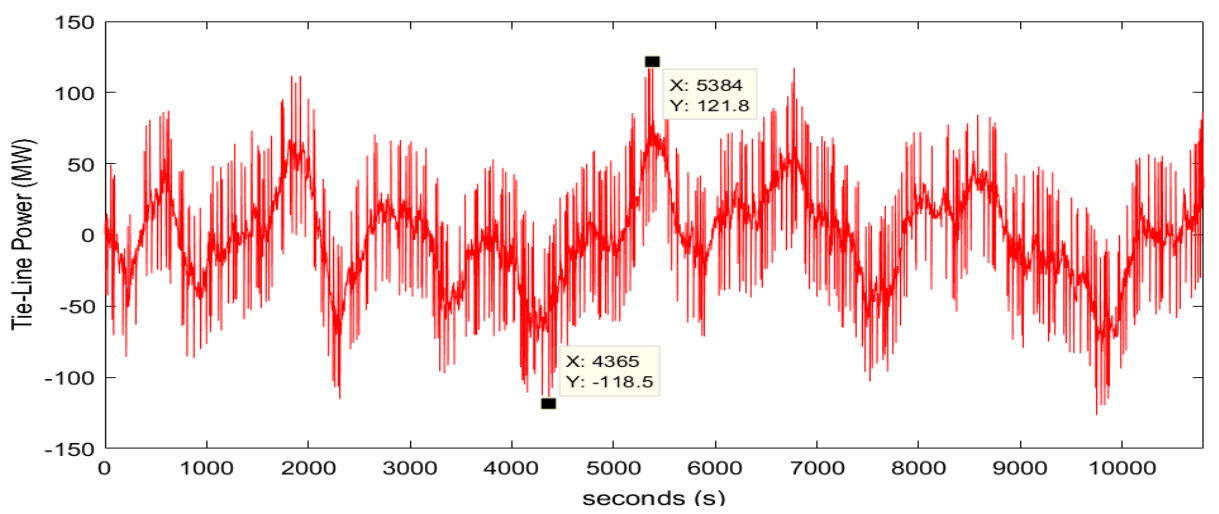

Figure 2. Tie-Line power for case 1 in MG1

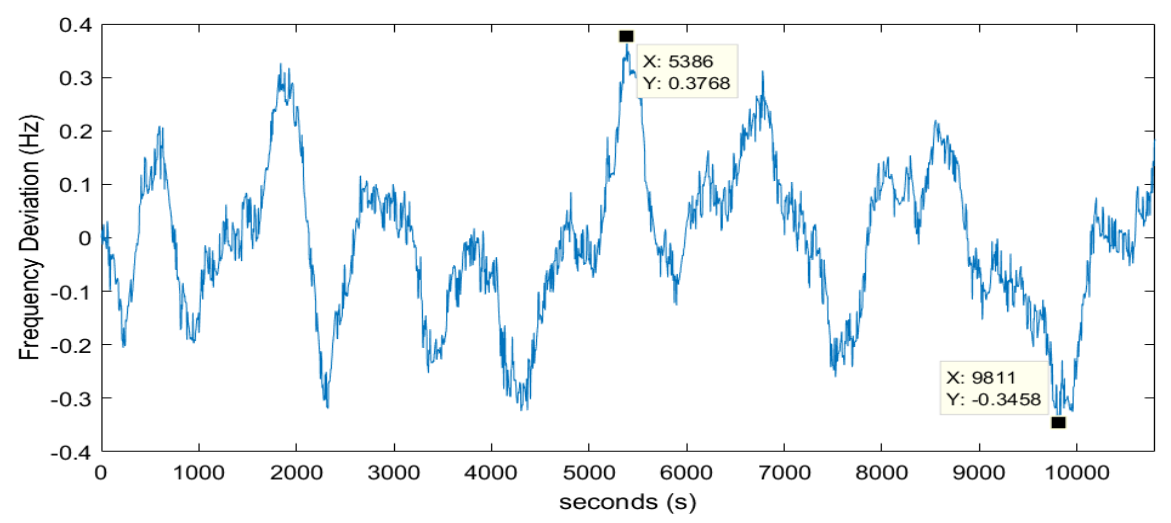

Figure 3. Frequency deviation for case 1 in MG1

Results in Figure 4 and 5 clearly show the frequency deviation between the two cases and it shows that the system is not stable as it varies fluctuation greater than the maximum permissible for frequency stability. In such a case, if the load is sufficiently high as compared to the power from generator then it will cause the frequency to decrease as it will take more energy for the generator to be able to endure with the newly increased load causing the generator rpm to drop and eventually the frequency drops. So, at a glance it already proves that to maintain the power system frequency stability and in advance to prevent the equipment from being damaged cause by instability of frequency, the power generation must be matched instantaneously with the power load.

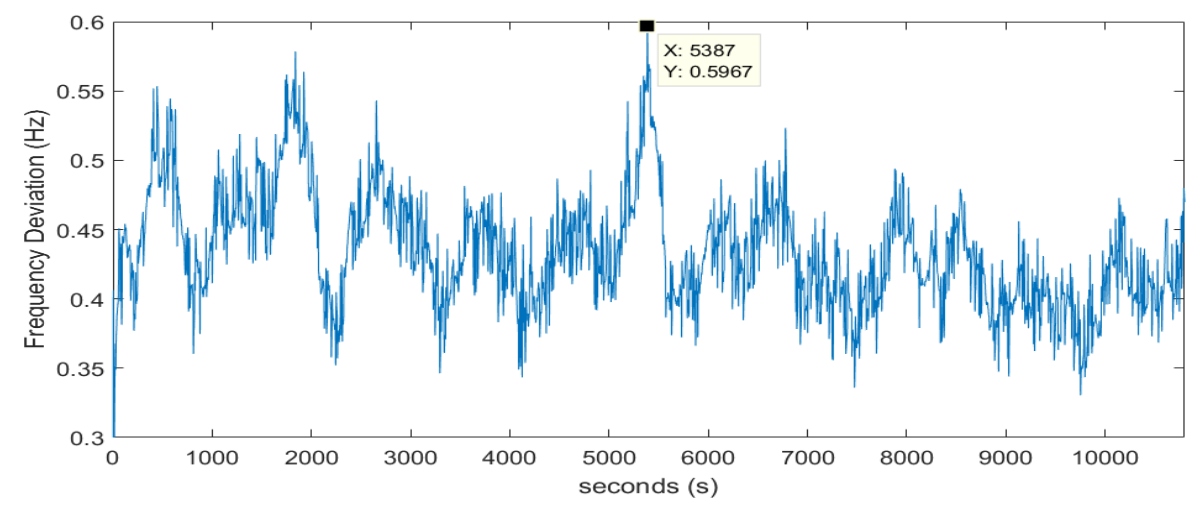

Figure 4. Frequency deviation for case 2 in MG1 


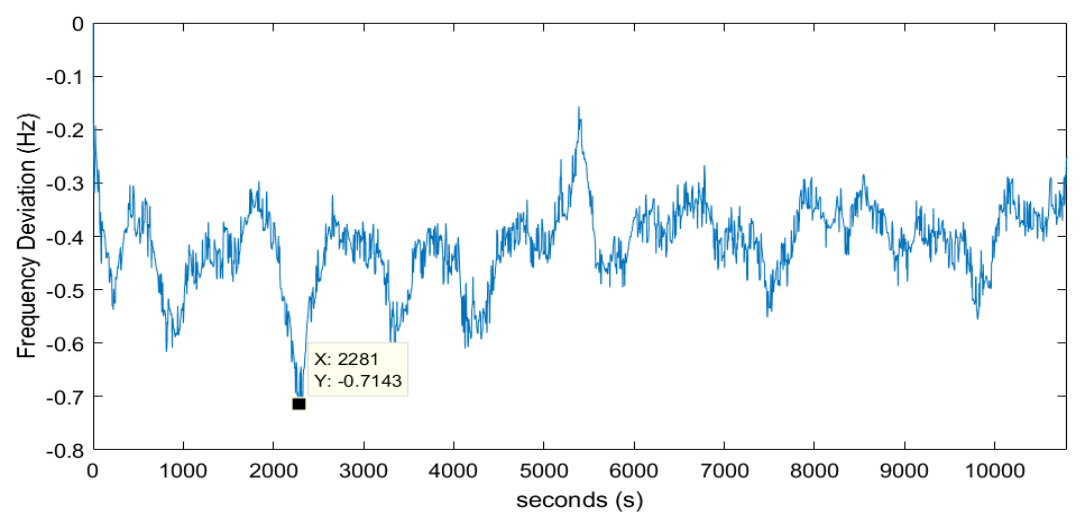

Figure 5. Frequency deviation for case 3 in MG1

\subsection{Multiple Micro Grid}

In this section another two micro grid are developed name as MG2 and MG3 with different capacity. This is to uptake with rational condition that possibly happen in real situation in the power system network which exposed to unpredictable event. Unlike previous section, no cases have been introduced here as all the power generated and consumed has been equalized reflected for stable operation.

\subsection{FCR Strategy}

It shows that by integrating all the three micro grid which is different in term of the capacity to system, they able to synchronized and stabilized after being compensated among each other as shown in Figure 6. Notably, one micro grid will be able to import and export power to the other micro grids as to maintain the stability in the entire the system. Likewise, the excessive power will be export to the other micro grid which has less power in order to cope with the power form the load demands.

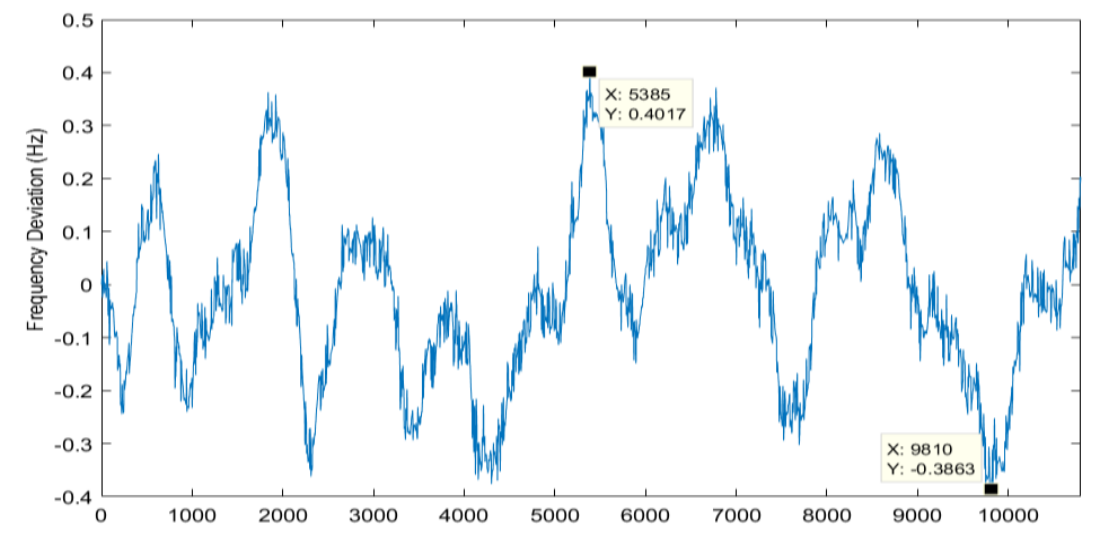

Figure 6. Frequency deviation of MG1, MG2 and MG3 with FCR strategy

Table 2 shows the maximum and minimum point for frequency deviation when bias value, $\beta$ is varied. Bias value here is an approximation used in the area control error (ACE). This already prove that the higher the value of $\beta$, it can suppress the frequency deviation as the power system will be more stabilize shown in Figure 7.

Table 2. Variation of $\beta$

\begin{tabular}{ccc}
\hline Beta & Min $\Delta f(\mathrm{~Hz})$ & $\operatorname{Max} \Delta f(\mathrm{~Hz})$ \\
\hline 1 & -0.3848 & 0.4017 \\
3 & -0.3045 & 0.3664 \\
5 & -0.224 & 0.3115 \\
\hline
\end{tabular}




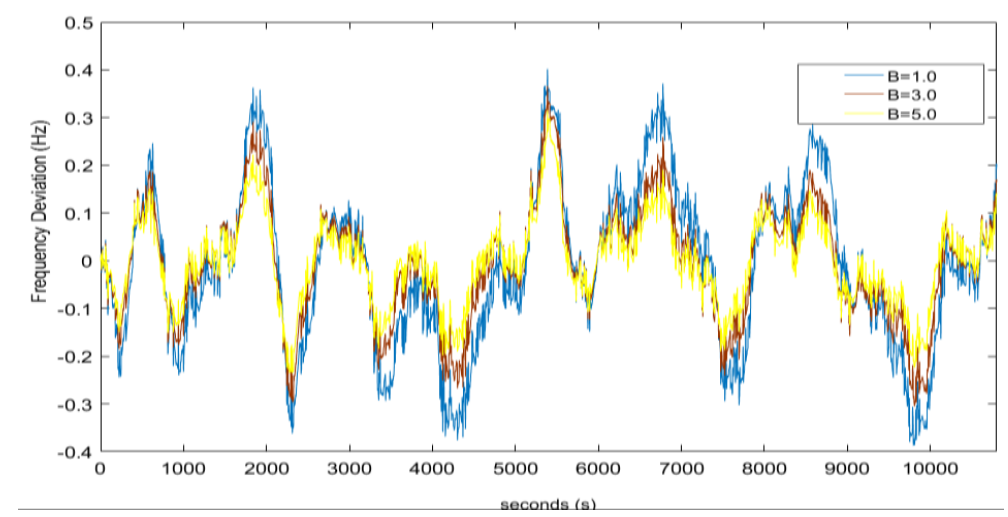

Figure 7. Frequency Deviation with Different Beta Setting

\section{CONCLUSION}

A Frequency Control Reserve (FCR) approach has been proposed to suppress frequency deviation in viewpoint of upward power system frequency stability. The proposed method explicitly relies on the ability of micro grids to import or export any excessive power from its own or neighbouring grid as to maintain equilibrium stage which in turns make the proposed solutions completely successful for each test cases. Three micro grids with different capacity has been developed for each case to verified the proposed method beforehand. Each of these grids generally interconnected to each other and power sharing between these micro grids is through the tie-lines power flow. The approach combines the capability in terms of excessive power regionally in the entire areas and applied the local control for frequency regulation considering all parameters such as system inertia and maximum penetration level. Results of application of the proposed method towards large system reveal that minimum and maximum level of frequency deviation could be affected by determining the suitable bias values $(\beta)$. Increasing this value affectively supress more frequency and it is better to be over biased eventually.

\section{ACKNOWLEDGEMENTS}

This research is fully funded by TIER 1 grant (U862) of Universiti Tun Hussein Onn Malaysia (UTHM). The authors gratefully acknowledge the support of the Universiti Teknikal Malaysia Melaka (UTeM) through Centre for Robotic and Industrial Automation (CeRIA) and Power Energy Focus Group, Advanced Technology Centre (ATC), Faculty of Engineering Technology, UTHM.

\section{REFERENCES}

[1] C. Yuen, A. Oudalov, and A. Timbus, "The Provision of Frequency Control Reserves from Multiple Microgrids," IEEE Trans. Ind. Electron., vol. 58, no. 1, pp. 173-183, 2011.

[2] C. Wang, Y. Mi, Y. Fu and P. Wang, "Frequency Control of an Isolated Micro-Grid Using Double Sliding Mode Controllers and Disturbance Observer," in IEEE Transactions on Smart Grid, vol. 9, no. 2, pp. 923-930, March 2018.

[3] J. Zhang, S. Su, J. Chen, and F. Hong, "Stability analysis of the power system with the large penetration ratios of microgrids," 1st Int. Conf. Sustain. Power Gener. Supply, SUPERGEN '09, vol. 411105, pp. 1-5, 2009.

[4] J. Li, J. Su, X. Yang, and T. Zhao, "Study on microgrid operation control and black start," DRPT $2011-20114$ th Int. Conf. Electr. Util. Deregul. Restruct. Power Technol., pp. 1652-1655, 2011.

[5] S. Dahal, N. Mithulananthan, and T. Saha, "Investigation of Small Signal Stability of a Renewable Energy Based Electricity Distribution System," IEEE PES Gen. Meet., pp. 1-8, 2010.

[6] G. Liang, S. R. Weller, J. Zhao, F. Luo and Z. Y. Dong, "The 2015 Ukraine Blackout: Implications for False Data Injection Attacks," in IEEE Transactions on Power Systems, vol. 32, no. 4, pp. 3317-3318, July 2017.

[7] B. A. Carreras, D. E. Newman and I. Dobson, "North American Blackout Time Series Statistics and Implications for Blackout Risk," in IEEE Transactions on Power Systems, vol. 31, no. 6, pp. 4406-4414, Nov. 2016.

[8] H. Golpîra, H. Seifi, A. R. Messina, and M. R. Haghifam, "Maximum Penetration Level of Micro-Grids in LargeScale Power Systems: Frequency Stability Viewpoint," IEEE Trans. Power Syst., vol. 31, no. 6, pp. 5163-5171, 2016.

[9] K. A. Qaid, C. K. Gan, N. B. Salim and M. Shamshiri, "Impacts of Large-scale Solar Photovoltaic Generation on Power System Frequency Response," 5th IET International Conference on Clean Energy and Technology (CEAT2018), Kuala Lumpur, 2018, pp. 1-8. 
[10] M. Braun et al., "The Future of Power System Restoration: Using Distributed Energy Resources as a Force to Get Back Online," in IEEE Power and Energy Magazine, vol. 16, no. 6, pp. 30-41, Nov.-Dec. 2018.

[11] D. Rodriguez Medina et al., "Fast Assessment of Frequency Response of Cold Load Pickup in Power System Restoration," in IEEE Transactions on Power Systems, vol. 31, no. 4, pp. 3249-3256, July 2016

[12] L. Chang-Chien, L. N. An, T. Lin and W. Lee, "Incorporating Demand Response with Spinning Reserve to Realize an Adaptive Frequency Restoration Plan for System Contingencies," in IEEE Transactions on Smart Grid, vol. 3, no. 3, pp. 1145-1153, Sept. 2012

[13] F. Guo, C. Wen, J. Mao and Y. Song, "Distributed Secondary Voltage and Frequency Restoration Control of Droop-Controlled Inverter-Based Microgrids," in IEEE Transactions on Industrial Electronics, vol. 62, no. 7, pp. 4355-4364, July 2015.

[14] B. S. Abdulraheem and C. K. Gan, "Power System Frequency Stability and Control: Survey," Int. J. Appl. Eng. Res., vol. 11, no. 8, pp. 5688-5695, 2016.

[15] T. Nguyen, H. Yoo and H. Kim, "A Droop Frequency Control for Maintaining Different Frequency Qualities in a Stand-Alone Multi Micro Grid System," in IEEE Transactions on Sustainable Energy, vol. 9, no. 2, pp. 599-609, April 2018.

[16] V. Gholamrezaie, M. G. Dozein, H. Monsef and B. Wu, "An Optimal Frequency Control Method Through a Dynamic Load Frequency Control (LFC) Model Incorporating Wind Farm," in IEEE Systems Journal, vol. 12, no. 1, pp. 392-401, March 2018.

[17] U. Rudez and R. Mihalic, "WAMS-Based Underfrequency Load Shedding with Short-Term Frequency Prediction," in IEEE Transactions on Power Delivery, vol. 31, no. 4, pp. 1912-1920, Aug. 2016.

[18] M. Karimi, P. Wall, H. Mokhlis and V. Terzija, "A New Centralized Adaptive Underfrequency Load Shedding Controller for Microgrids Based on a Distribution State Estimator," in IEEE Transactions on Power Delivery, vol. 32, no. 1, pp. 370-380, Feb. 2017.

[19] Y. Tofis, S. Timotheou and E. Kyriakides, "Minimal Load Shedding Using the Swing Equation," in IEEE Transactions on Power Systems, vol. 32, no. 3, pp. 2466-2467, May 2017.

[20] A. Saffarian and M. Sanaye-Pasand, "Enhancement of Power System Stability Using Adaptive Combinational Load Shedding Methods," in IEEE Transactions on Power Systems, vol. 26, no. 3, pp. 1010-1020, Aug. 2011.

[21] P. V. Brogan, R. J. Best, D. J. Morrow, K. McKinley and M. L. Kubik, "Effect of BESS Response on Frequency and RoCoF During Underfrequency Transients," in IEEE Transactions on Power Systems, vol. 34, no. 1, pp. 575-583, Jan. 2019.

[22] S. Chen, T. Zhang, H. B. Gooi, R. D. Masiello and W. Katzenstein, "Penetration Rate and Effectiveness Studies of Aggregated BESS for Frequency Regulation," in IEEE Transactions on Smart Grid, vol. 7, no. 1, pp. 167-177, Jan. 2016.

[23] H. Kim, E. Shin, Y. Lee, J. Kim and B. M. Han, "Smooth Operation Transition Scheme for Stand-Alone Power System with EG and BESS-PV Panels," in IEEE Transactions on Smart Grid, vol. 8, no. 4, pp. 2042-2044, July 2017.

[24] S. K. Tiwari, B. Singh and P. K. Goel, "Control of Wind-Diesel Hybrid System with BESS for Optimal Operation," in IEEE Transactions on Industry Applications, vol. 55, no. 2, pp. 1863-1872, March-April 2019.

[25] A. Zainuri, U. Wibawa, M. Rusli, and R. N. Hasanah, "VRLA Battery State of Health Estimation Based on Charging Time," vol. 17, no. 3, pp. 1577-1583, 2019.

[26] T. A. Nugroho, R. S. Wijanarko, H. Setiadi, D. T. Elektro, U. Pertamina, J. Teuku, N. Arief, and S. Lucia, "Coordination of Blade Pitch Controller and Battery Energy Storage using Firefly Algorithm for Frequency Stabilization in Wind Power Systems," vol. 17, no. 2, pp. 1014-1022, 2019.

[27] N. Bin Salim, H. Aboelsoud, T. Tsuji, T. Oyama, and K. Uchida, "Load Frequency Control of Two-Area Network using Renewable Energy and Battery Energy", IEEJ,vol. 6, 2017

\section{BIOGRAPHIES OF AUTHORS}

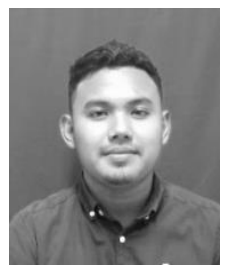

Mohamad Syamin Bin Zainal Abidin completed his Diploma in Electrical Engineering in 2016 before obtained his Bachelor`s degree Malaysia in 2019 from Universiti Teknikal Malaysia Melaka (UTeM). He is currently working at Intemep Sdn Bhd as Construction Engineer.

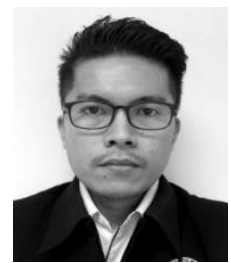

Norhafiz Bin Salim obtained his Bachelor`s degree from Universiti Teknikal Malaysia Melaka (UTeM) Malaysia in 2007, Msc. degree from Universiti Teknologi Malaysia (UTM), in 2009 and Dr. Eng. degree from Yokohama National University (YNU), Japan in 2017. Since 2007 he has been with UTeM as a tutor, lecturer and currently a senior lecturer in the Department of Electrical Engineering. His current research is centered on frequency/voltage stability assessment and analysis with distributed energy resources. 

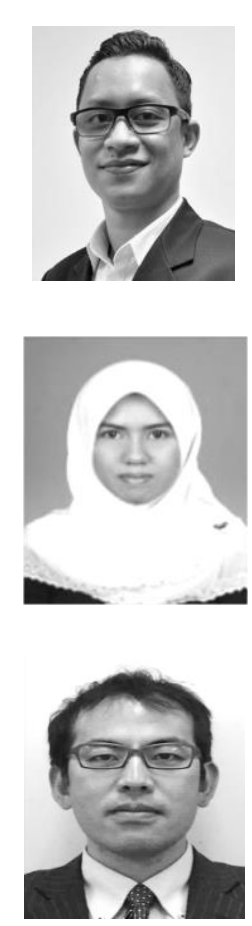

Aimie Nazmin Azmi received his B.Eng in electrical engineering (industrial power) from Univeristi Teknikal Malaysia Melaka, in 2006. He works at Intel Microelectronics (M) before pursue his study in M.Eng.Sc in energy system from The University of New South Wales, Sydney in 2010. He received his PhD in Renewable Energy from University of Agder, Norway in 2017. His research interest is in renewable energy, energy system and zero energy building (ZEB).

Nor Aira Binti Zambri received her BSc from Universiti Kebangsaan Malaysia in 2007 and MEng from Universiti Teknologi Malaysia in 2010, respectively. She received her $\mathrm{PhD}$ on electrical power engineering from Universiti Kebangsaan Malaysia in 2015. Currently, she works as senior lecturer in Universiti Tun Hussein Onn Malaysia and she can be reached at aira@uthm.edu.my.

Takao TSUJI received his Dr. Eng. degree from Yokohama National University, Japan, in 2006. In April of the same year, he was appointed as a Research Associate in the Graduate School of Information Science and Electrical Engineering of Kyushu University. Since April of 2007, he has been with the Faculty of Engineering at Yokohama National University, Japan and is currently an Associate Professor. His research interests include the planning, operation, and control of electric power systems. Prof. Tsuji is a member of IEEJ. 